\title{
Development of a Modular Home Construction Kit using the Rammed Earth Building Technique
}

\author{
Valmiki K Sooklal \\ Assistant Professor \\ Systems and Mechanical Engineering \\ Southern Polytechnic State University \\ vsooklal@spsu.edu
}

\begin{abstract}
In developing countries where resources are limited, the task of providing shelter for poverty stricken communities that are already in dire need of basic amenities can be a daunting one. This paper proposes a solution to this housing issue in the form of a modular home construction kit. These kits will provide such communities with a tool for sustainably constructing their own dwellings using local manpower combined with the natural resources available on site. The technique is based on the rammed earth principle in which the raw material for the construction process is primarily the natural soil present at the targeted location. This result in considerable savings in terms of sourcing and transporting costs of building materials typically used in traditional constructions methods. In addition, heavy or powered equipment is not needed for this construction technique making it a viable option for places where an electrical power supply or fuel source is not available.

The project is part of a service-learning program, recently introduced at the University of Colorado at Colorado Springs to afford students an opportunity to work on a multidisciplinary team while using their engineering knowledge to provide solutions to real world problems. The student team working on the project has been involved in developing all the necessary procedures for assessment of the location's soil type as well as the design and sourcing of the kit components. They will also be required to develop the necessary instructional and training material to allow for assembly of the kit components and the implementation of the technique to produce a finished structure (excluding the roof).
\end{abstract}

Index Terms -Modular housing kit, Panels, Rammed Earth, Sustainable

\section{INTRODUCTION}

In developing countries where resources are limited, providing shelter for poverty stricken communities that are already in dire need of basic amenities can be daunting. The problem is further compounded by the lack of educational resources coupled with high illiteracy rates. In addition, most rural communities are not always eager to accept help from foreign entities that are not sensitive to their cultural, ethnic or social requirements.

The aim of the project is to provide communities in a resource-limited setting with a tool for sustainably constructing their own dwellings using local manpower combined with the natural resources available on site. The technique is based on the rammed earth principle in which the raw material for construction is the natural soil present at the targeted location.

This paper outlines the development of a modular housing kit based on the rammed earth technique that provides a low cost solution to the housing issue while including input from the 
community in the construction process. The approach described herein has been developed with the assistance of a team of engineering students as part of their senior design project. The project is part of a service-learning program at the University of Colorado at Colorado Springs, introduced to afford students the opportunity to put their skills and education to use in the service of others.

\section{Background}

Earthen materials, together with the rammed earth technique, have been used in construction since time immemorial. Sections of the Great Wall of China, which is approximately 2,000 years old, were constructed of rammed earth and are still in existence today ${ }^{1}$. Rammed earth construction can be found in North Africa, Australia, regions of North and South America, China and Europe, including France, Germany and Spain ${ }^{2}$.

Today the technique is attracting renewed interest throughout the world. Rammed earth walls are manufactured by compacting a clayey soil (earth) into a formwork. The composition of the earth used for the construction should contain no organic material and a sufficient quantity of clay acting as a binder between the grains - a mixture of silt, sand, gravel and stones with diameters of a few centimeters.

Compaction of such a mixture with the appropriate water content is considered optimum, i.e. providing the highest dry density for a fixed compaction energy. This process is called the dry method because the water content is about $10 \%$, while a paste (in the case of adobes) should have a water content of about $25 \%$. The rammed earth is composed of several layers of earth roughly $15 \mathrm{~cm}$ thick, poured into a formwork (wooden or metal), and rammed with a rammer (manual or pneumatic). After compaction, each layer is $8-10 \mathrm{~cm}$ thick. This procedure is repeated until completion of the wall ${ }^{3}$.

\section{Social aspects}

\section{IMPACT ON COMMUNITY}

Projects without a local component or active community involvement stand a greater chance of falling flat and destroying community cohesion ${ }^{4}$. When the community in question has a vested interest in a project and is allowed to actively participate in the process rather than taking the observer role, a more effective solution to the task at hand is achieved. The development of a modular housing kit addresses this issue by allowing the structure's dimensions to be modified on site during the construction process. In addition, since the kit is designed for wall construction and not a building plan, future residents have the flexibility during the building phase to include functional and lifestyle elements that would normally be overlooked by designers who are unaware of the community's needs.

\section{Training}

As part of the deliverables, the student team was required to produce a detailed manual and construction guide to easily facilitate the implementation phase of the project. The manual will be used to train and educate the most capable members of the community in the rammed earth building technique. It is the hope that after becoming proficient they will pass the knowledge they gained on to others, thereby allowing them to not only construct their own dwellings but learn a useful skill. 


\section{DESIGN CONSTRAINTS}

The student design team was charged with designing a modular home construction kit utilizing rammed earth as the building method. The kit would allow end users to construct walls of various dimensions made from compacted (rammed) earth from the same basic kit. To achieve this goal the kit must meet the following design requirements:

- Low weight and compact size.

- Maximum overall cost of $\$ 20,000$

- Provide safe construction of up to 10 houses from a single kit (excluding the roof)

- Sufficiently robust in terms of resistance to impact to allow it to be dropped off at remote locations and durable enough to withstand the effects of the elements

- Allow for some degree of customization of building plans.

- Include detailed instructions for every aspect of the construction.

- Easily transported to construction site.

\section{SOIL ANALYSIS}

The ideal composition for soil used in rammed earth construction is approximately $30 \%$ clay and silt and $70 \%$ sand $^{5}$ with around $12 \%$ (by volume) of water ${ }^{6}$. In order for a soil sample to be used for rammed earth construction, the soil must produce rammed earth that has a compressive strength of at least 300 psi. A soil sample will be collected from the location under consideration and returned to the materials laboratory at the university for testing.

There are three tests that are considered standard for determining the strength of a soil specimen:

1. Sedimentary test: This test gives an approximate percentage of the various soil types present within a soil sample. The main soil types considered were sand, gravel, clay, and silt. Sand and gravel encompass the course aggregate found within the soil and serve as the main constituent in the desired mix. Ideally, the mixture should be composed of $70 \%$ sand (or fine gravel), but a range of $60 \%$ to $80 \%$ is also acceptable. If the soil composition is outside of this range, varying amounts of sand or cement may be added to modify the mixture in order to achieve the necessary build strength. If the mixture consists of more than $80 \%$ sand, the mixture would lack the amount of clay/silt necessary to bond completely and would be more susceptible to failure. This could be rectified through the addition of cement to the mixture to act as an additional bonding agent.

2. Moisture test: This test assists in determining how much water must be added in order to ensure that the maximum strength of the cured rammed earth would be achieved. If too much water was present in the soil during compaction, then the curing time of the structure would be much longer. If too little water was present in the soil during compaction, it would have a negative impact on the binding capabilities of the soil. The test involved compressing a small ball of dirt in one's hand and gauging its feel, as well as analyzing how much it would break apart when dropped from waist height. The ideal moisture content for rammed earth construction is typically found to be $12 \%{ }^{7}$. 
3. Compressive strength test: The final test, known as the proctor test, gives the compression strength of the rammed earth. The standard procedure for the proctor test was dictated by ASTM D698, which sets the guideline for sample creation.

The data received from these three tests would then be used to determine if any additives are needed and if the soil could reach the established strength standards. In order to validate the testing procedures the team produced a total of ten cylindrical specimens with dimensions of $76.2 \mathrm{~mm}$ ( 3 inches) in diameter and between $63.5-76.2 \mathrm{~mm}$ (2.5-3.0 inches) in height as shown in Figure 1. All ten specimens were produced from various combinations of the following three separate soil samples:

- Commercial white sand

- Commercial red clay

- Soil collected from the Campus at Colorado Springs

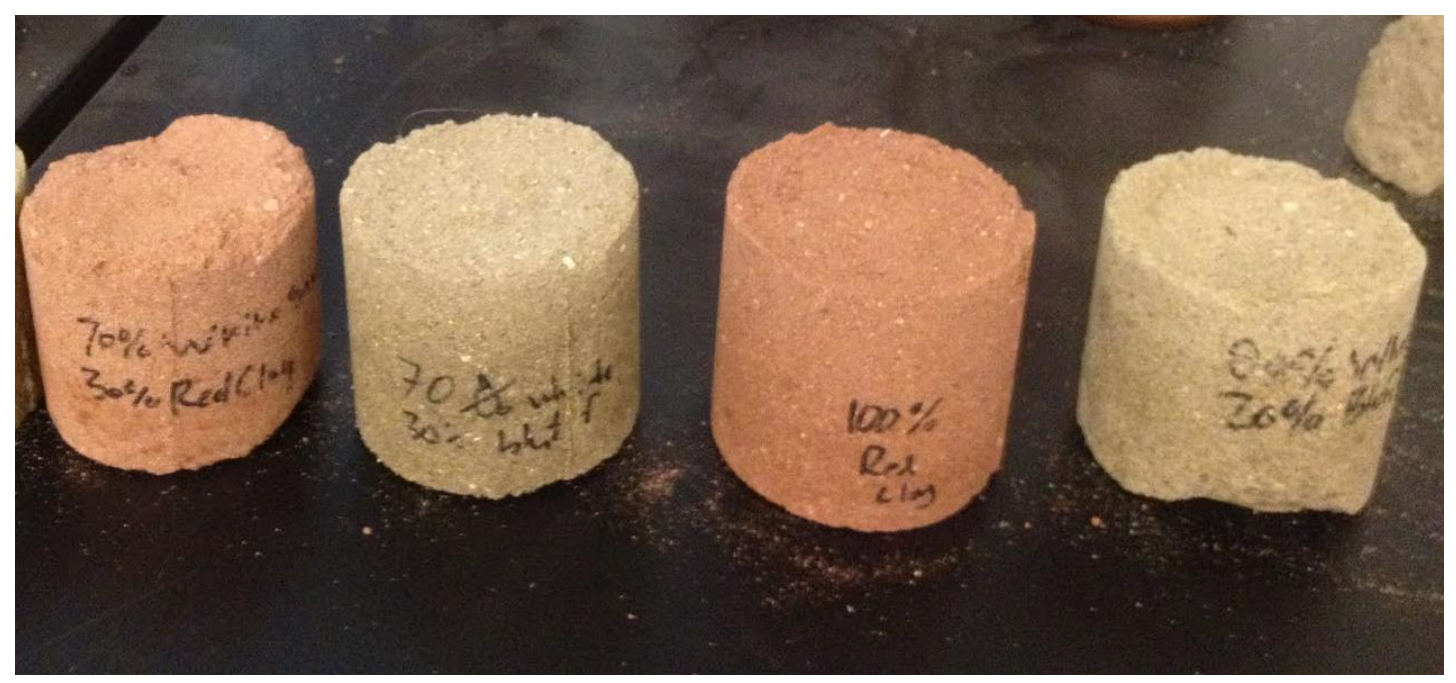

FIGURE 1

COMPRESION TEST SPECIMENS

All specimens were left to cure for at least one week. The compression tests were performed using an Instron 5900 series universal testing machine and the results are shown in Table 1. 


\section{TABLE 1}

\begin{tabular}{|c|c|c|c|c|c|c|c|}
\hline & APRESS & EST & ULTS FU & VARIUUS & PECIME & VIP & TIONS \\
\hline $\begin{array}{l}\text { Sample } \\
\text { Number }\end{array}$ & $\begin{array}{l}\text { White sand } \\
(\%)\end{array}$ & $\begin{array}{l}\text { Red clay } \\
(\%)\end{array}$ & $\begin{array}{l}\text { Campus soil } \\
(\%)\end{array}$ & Water (\%) & Sand $(\%)$ & $\begin{array}{l}\text { Clay } \\
(\%)\end{array}$ & $\begin{array}{l}\text { Maximum } \\
\text { Stress (psi) }\end{array}$ \\
\hline 1 & 65 & 35 & 0 & 20 & 88.5 & $\begin{array}{r}11 . \\
5\end{array}$ & 246.5 \\
\hline 2 & 70 & 0 & 30 & 3.5 & 73 & 27 & 40.8 \\
\hline 3 & 80 & 0 & 20 & 12 & 82 & 18 & 78.2 \\
\hline 4 & 70 & 0 & 30 & 12 & 73 & 27 & 137.4 \\
\hline 5 & 70 & 30 & 0 & 12 & 90.1 & 9.9 & 104.7 \\
\hline 6 & 0 & 100 & 0 & 12 & 67 & 33 & $105.6^{\Delta}$ \\
\hline 7 & 0 & 100 & 0 & 10 & 67 & 33 & 224.9 \\
\hline 8 & 0 & 100 & 0 & 12 & 67 & 33 & 288.1 \\
\hline 9 & 0 & 100 & 0 & 15 & 67 & 33 & 276.8 \\
\hline 10 & 0 & 100 & 0 & 20 & 67 & 33 & 232.1 \\
\hline
\end{tabular}

${ }^{\Delta}$ The top of specimen was not completely level

Sample number 1 produced near build-quality results, with a compressive strength of 246 psi. Samples 2 through 6 were significantly lower than build-quality. Samples 7 through 10 are all comprised of red clay and have varying water contents $(10 \%, 12 \%, 15 \%$, and $20 \%$ respectively). Compression testing on these specimens indicated that compressive strength increased with water content up to a maximum around $12 \%$ and then decreases with additional water. The $12 \%$ water content specimen displayed a compressive strength of 288 psi. Although this specimen did not meet the minimum 300 psi, with slight modifications this soil would likely be adequate to produce a rammed earth structure.

\section{PHASE I: KIT DEVELOPMENT}

This phase involved the development of an optimal design through an iterative process of concept generation and evaluation. A modular kit was developed based on the design constraints outlined earlier. In order to make the kit affordable compared to current options on the market, the following factors were examined:

- The dimensions of the house

- The number of people necessary to complete construction of one house

- The amount of time that it would take to build a single unit

Three specific companies/methods emerged as the current market leaders: Habitat for Humanity, Hydraform, and adobe bricks. Habitat for humanity is a non-profit organization that builds houses all around the world in various settings. As a result, it would be unrealistic to attempt to generalize their building techniques for the purpose of comparison to homes that would be constructed using the modular kit design. To this end only the houses built by Habitat for Humanity in third world countries were considered. The average house built by Habitat for Humanity in developing countries is $300 \mathrm{ft}^{2}-350 \mathrm{ft}^{2}$, with a cost of $\$ 1,800-\$ 2,500$ (for material only). It usually takes 3-5 weeks to build a house with an average work force of 15 people. 
Only a few of the workers have previous knowledge of home construction, with a majority of the workers having relatively little to no experience in home construction ${ }^{8}$.

Hydraform is a company based out of South Africa that manufactures portable brick making machines. These machines work by taking soil and compressing it into bricks. They can produce anywhere from 1500-3000 bricks per day, with a team of 9-18 workers per machine. However, for the first seven days after the bricks have been produced, they must be placed under plastic and sprayed down with water several times. The bricks must then cure for an additional 7-14 days before they are able to be used in construction. Hydraform builds a wide range of brick making machines. These machines range in size, price, portability and power supply ${ }^{9}$.

Adobe bricks have been used for thousands of years worldwide as a way to construct buildings. The process for producing the bricks has remained essentially unchanged. Soil is mixed with water and some form of binding material, such as straw or grass, and then packed into forms. The bricks are then taken out of the forms and left to sit in the sun and cure for 3-4 weeks. During the curing process $30-40 \%$ of the bricks crack and are unusable ${ }^{7}$.

After considering the current options it was decided that the kit should be developed to produce a $400 \mathrm{ft}^{2}$ house. This size was chosen because it was slightly larger than what Habitat for Humanity currently uses, but was still within a reasonable range. The kit would allow for up to 15 workers all working on one house at a time. The house structure (excluding the roof) should be completed in 3 weeks. The number of workers was chosen because it is similar to what Habitat for Humanity currently uses and was just above the average number of workers that Hydraform employs to operate their machinery.

The weight of the kit was set to be less than $23,000 \mathrm{lbs}$ with a total volume no bigger than 9'8" x7'8' 7 7'10". These values came from the dimensions and weight capacity of half of a standard shipping container. This was motivated by the final goal of being able to ship two complete kits in one shipping container [17]. In order to give the builder the capability to build multiple houses with the contents of one kit. Having a kit that can produce several houses significantly decreases the cost per house, since most of the tools in the kit could be re-used on additional houses.

It costs Habitat for Humanity $\$ 1,800-\$ 2,500$ per house. After looking at all of the constraints already set, the cost per house goal for this project was set at $\$ 2,000$ for constructing the building shell. This would make the kit competitive with Habitat's current options, and also be able to meet the other customer requirements. The houses are also required to be customizable. The level of customization that the kit offers will improve customer satisfaction by allowing for each house to suit individual tastes.

\section{PHASE II: FINAL DESIGN}

\section{Concrete forms}

Concrete forms were selected to produce a stable boundary against which the walls of a rammed earth home could be compacted. Many types of these forms exist, but the most versatile may be Symons concrete forms. These forms are made from plywood that is supported by a steel framework ${ }^{10}$. The durability of these forms makes them ideal for use in a reusable kit. The main form dimension included in the kit would be $2^{\prime} \times 4^{6}$. A number of smaller size panels would also be included, such as 2'x3' panels and adjustable panels. The 2'x3' panels and the adjustable panels are included to provide an incredible amount of creativity and customization for the 
builders. They allow for the placement of a window or door in any of several possible locations to suit builders' tastes.

\section{Modules}

The main obstacle in the design of this kit was making the kit both inexpensive and mobile. The solution to these issues was the use of different modules in the kit as a whole. Each module was basically a kit in itself, each holding a different building block with which a rammed earth home could be built. The whole kit was split up into 5 modules:

- Panels

- Reusable hardware

- Non-reusable hardware

- Window and door design

- Soil analysis

These five modules aided in lowering the kit price, because if only one module was needed, only one module need be purchased. A good example of this is the purchase of the non-reusable hardware module after the kit's allotted ten houses have been completed. The modules also aid in the kit's mobility by splitting the large kit into smaller sections. The modules were further broken down into sections that could be easily transported by one or two people.

\section{Layer by Layer Construction}

Perhaps one of the greatest challenges was devising a way to decrease the number of panels the kit required, thereby reducing the weight and cost while maintaining the kit's versatility. Including enough panels to build an entire house at once was out of the question; a house that has a 20'x20' inner perimeter would require around 200 panels to frame in its entirety. The solution to this problem was a layer-by-layer construction technique. Panels would be placed in rows around the perimeter of the house (with 2'x4' panels lying with their 4' sides horizontal). Initially, two of these rows would be placed on top of each other with ties connecting the inner panels to outer panels and soil would be compacted within them. Then, the bottom row of forms could be removed. The upper row of forms would be held in place by friction due to the compressed soil within and the ties connecting the inner and outer rows of panels. The former first layer of forms would then be reinstalled as the third layer of forms. Soil would then be compressed in this new layer, and the process would be repeated until the desired wall height was reached. Figures 2-4 demonstrates the process. 
International Journal for Service Learning in Engineering, Humanitarian Engineering and Social Entrepreneurship Vol. 10, No. 1, pp. 24-37, Spring 2015

ISSN 1555-9033

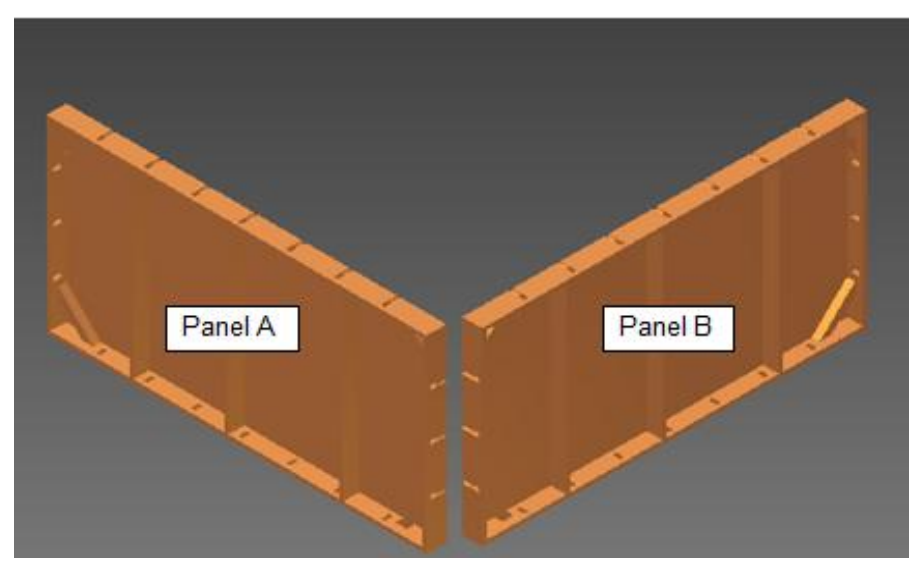

FIGURE 2

ASSEMBLY OF CORNER PANELS

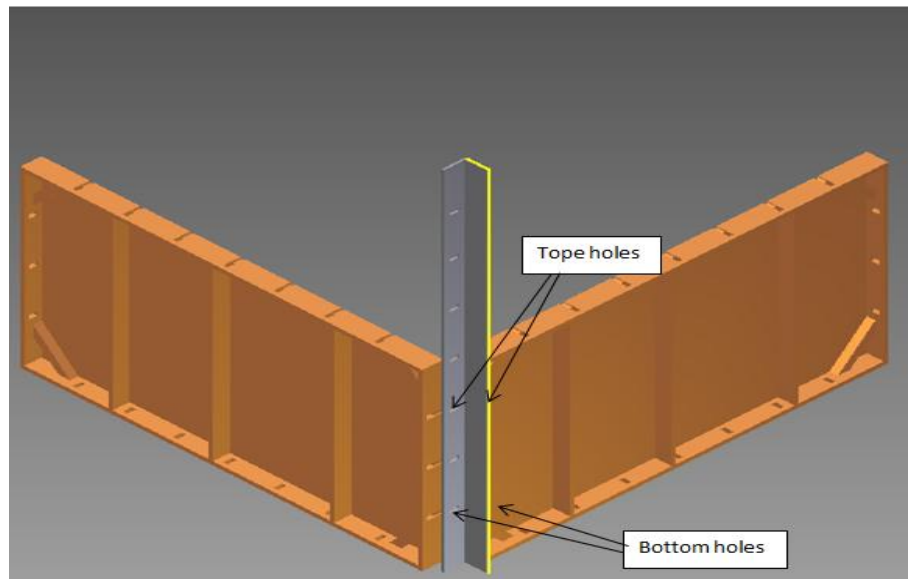

FIGURE 3

WEDGE BOLTS AND CORNER PIECE USED TO SECURE BOTH PANELS 


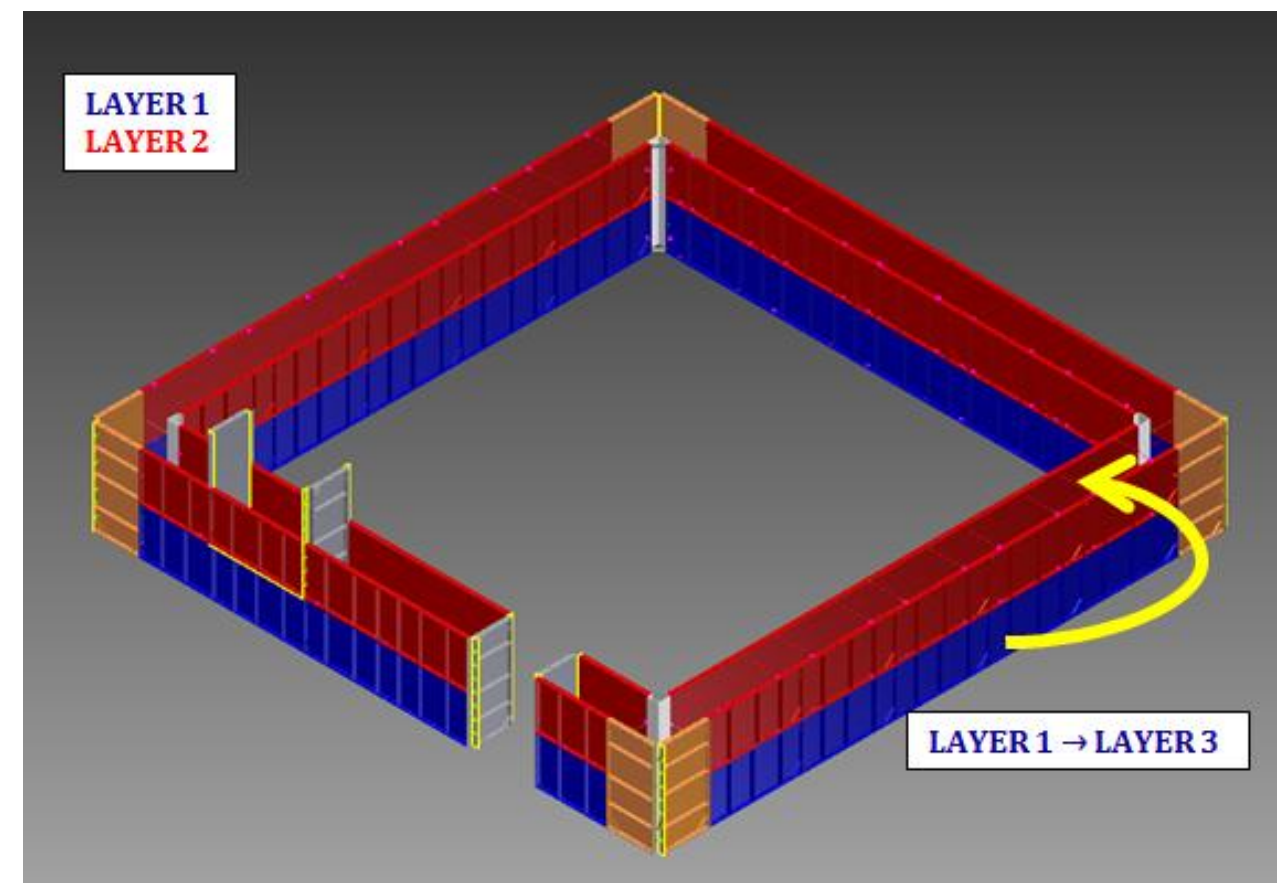

FIGURE 4

COMPLETION OF TWO LAYERS IN THE CONSTRUCTION PROCESS

\section{Construction Procedure}

In order to build a rammed earth home, the topsoil of the construction area must first be completely removed. The next step in construction involves the following tasks that can be completed simultaneously:

- Soil excavation

- Soil preparation

- Soil transportation

- Panel assembly

- Soil compaction

The soil from the initial excavations is stockpiled for use in the construction process. At this stage deficiencies in soil content are adjusted to produce a soil fit for rammed earth construction. The Symons concrete forms are assembled into their layers in accordance with the layer-by-layer construction technique. The completed soil mixture is then transported from the preparation site to the construction site, pouring the soil into the forms to be compacted. Workers then use manual tampers to compress the soil within the forms.

\section{Soil Compaction}

Manual tamping was determined to be the most feasible means of compacting soil within the forms. In the United Stated, hydraulic tampers are usually used because of their increased performance. However, in developing countries the power required to operate these kinds of tampers would likely not be available. Despite the fact that manual compaction requires more time, it was determined to be the best way to construct rammed earth structures in developing countries. 


\section{Window and Door Design}

Creating windows and doors in a rammed earth house posed an interesting challenge. In order to create a gap in the solid earth walls, bulkheads were used and attached to the forms to produce a rigid wall against which the soil could be compacted. In order to preserve reusability of the kit, it was decided to use additional Symons forms as the bulkheads. The bulkhead panels can be either 18 " $\times 3$ ' or 18 " by 4' depending on the desired size of the window. These bulkheads are attached to the standing forms with outside corner pieces as shown in Figure 5-6.

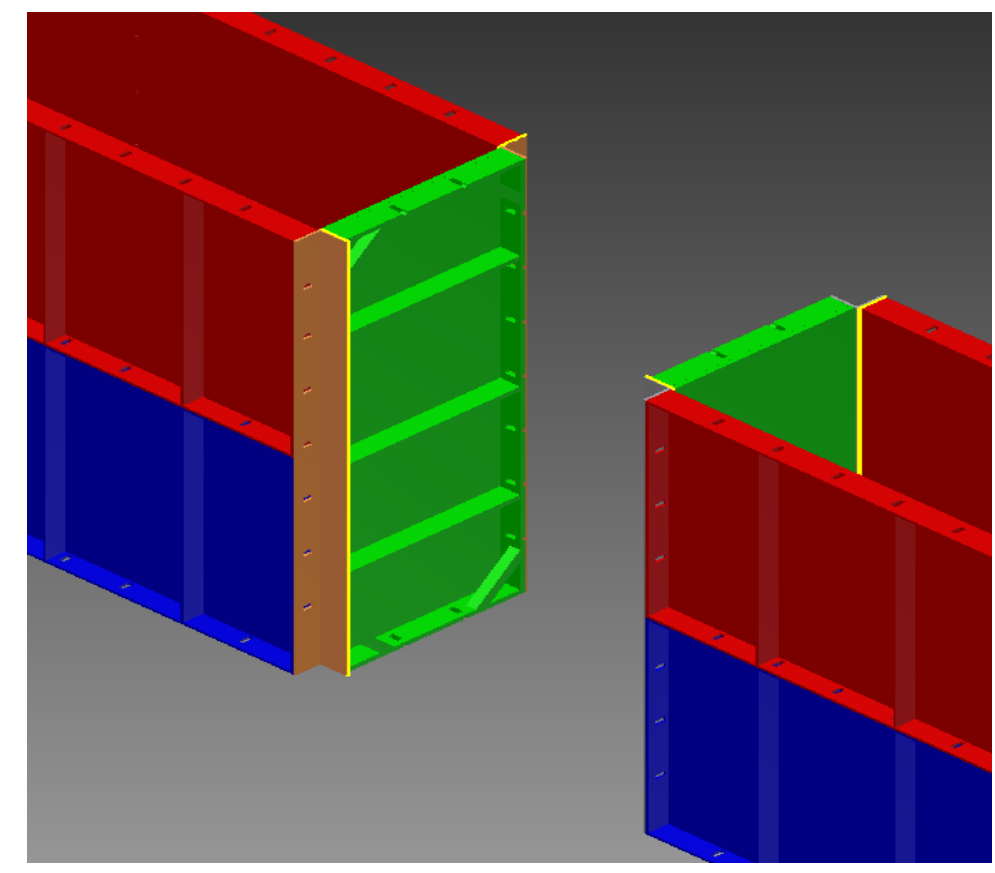

FIGURE 5

BULKHEAD PANELS USED FOR DOOR CONSTRUCTION

In a similar fashion, a solid surface would be necessary to assure that soil could be compacted into a beam above a window or door. Again, bulkhead panels were decided upon to provide this solid surface. 


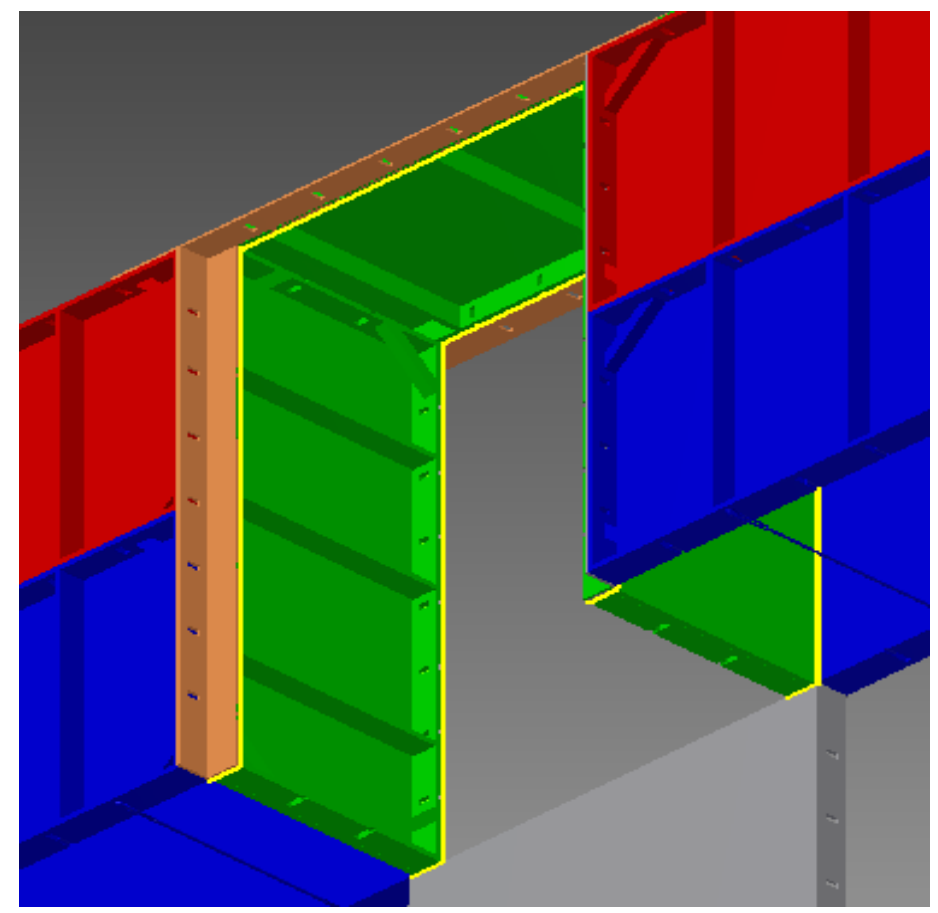

FIGURE 6

\section{BULKHEAD PANELS USED FOR DOOR CONSTRUCTION}

These bulkhead panels must be removed after construction, and additional support is necessary to produce a structurally sound beam. This additional support comes from the inclusion of glue-laminated beams of wood that are stacked to produce the support lintel. The lintel is produced from four $13 / 4 \mathrm{in}$. by $18 \mathrm{in}$. by $5 \mathrm{ft}$. planks placed on top of each other with at least 6 inches (depending on the size of the window) overlapping the rammed earth walls on either side of the window or door.

\section{Lintel Load Support Verification}

The designed kit has the flexibility for windows and doors to be either 3 feet or 4 feet wide. A lintel is required to support the rammed earth beam on top of the window and door openings. The size of the included lintel beams were calculated for a 4 foot span so that the included lintel pieces would work for both possible sizes. For a 4 foot span, the minimum thickness of lintel is approximately 6 inches. The Glulam beams used in this kit have dimensions of $13 / 4 \times 18 \times 60$ inches. It is important to note that 1 foot of the total beam length overlaps the rammed earth walls to anchor the lintel, equating to a series of beams that are 4 feet long and loaded in bending. To fulfill the 6 inch requirement, four of the Glulam beams must be stacked vertically on top of each other.

Since the transverse shear stress between the un-bonded beams is considered negligible, the four identical beams will each take $1 / 4$ of the total load ${ }^{11}$. The total load $F_{R E}$, due to the weight of rammed earth can be calculated using the following: 


$$
F_{R E}=\rho L W H=0.07948 \frac{\mathrm{lb}}{\mathrm{in}^{3}}(18 \mathrm{in})(18 \mathrm{in})(48 \mathrm{in})=1236.07 \mathrm{lbs}
$$

where $\rho$ is the soil density, and $L, W$ and $H$ are the length, width and height respectively of the rammed earth beam.

The weight of the four (4) Glulam beams is calculated similarly:

$$
F_{G L}=4 \rho L W H=4\left(0.01987 \frac{\mathrm{lb}}{\mathrm{in}^{3}}\right)(1.75 \mathrm{in})(18 \mathrm{in})(48 \mathrm{in})=120.17 \mathrm{lbs}
$$

The total weight, $F_{\text {total }}$, is $1356.25 \mathrm{lbs}$, of which one-quarter is applied to each beam as a distributed load along the beams' lengths.

$$
F_{\text {individual }}=\frac{F_{\text {total }}}{4}=339.06 \mathrm{lbs}=F
$$

Now, maximum stress, $\sigma_{\max }$ and deflection, $\delta_{\max }$ of each beam can be calculated. The distributed load density $w$ equals the load $F$ divided by length $L$. The modulus of elasticity, $E$, of glulam beams is approximately $1.8 \mathrm{E} 6 \mathrm{psi}^{12}$.

$$
\begin{gathered}
\delta_{\text {max }}=\frac{5 w_{o} L^{4}}{384 E I}=\frac{5\left(\frac{F}{L}\right) L^{4}}{384 E I}=\frac{5 F L^{3}}{384 E I}=\frac{5(339.06 \mathrm{lbs})(48 \mathrm{in})^{3}}{384\left(1.8 \times 10^{6} \mathrm{psi}\right)\left(\frac{1}{12}\right)(18 \mathrm{in})(1.75 \mathrm{in})^{3}} \\
\therefore \boldsymbol{\delta}_{\text {max }}=\mathbf{0 . 0 3 3 7 \mathrm { in }} \\
\sigma_{\max }=\frac{M c}{I}=\frac{\frac{w_{0} L^{2}}{8}\left(\frac{h}{2}\right)}{\frac{1}{12} b h^{3}}=\frac{\frac{P}{L} L^{2}}{\frac{4}{3} b h^{2}}=\frac{339.06 \mathrm{lbs}(48 \mathrm{in})}{\frac{4}{3}(18)(1.75 \mathrm{in})^{2}} \\
\therefore \boldsymbol{\sigma}_{\text {max }}=\mathbf{2 2 1 . 4} \mathbf{p s i}
\end{gathered}
$$

The minimum yield strength of Douglas fir is approximately $2,600 \mathrm{psi}^{13}$. The lintels will therefore provide adequate support to the rammed earth above the windows and doors of the house.

\section{PHASE III: IMPLEMENTATION}

Pending funding, the design documentation generated from the previous phases will be used to produce a full-scale prototype. This rammed earth structure will be used to validate the design and identify those areas that require improvement. It will also be used as a pilot construction 
project for potential clients such Habitat for Humanity International for deployment in areas that where standard building materials are not readily available. This task will culminate with a refined and finalized set of design documentation.

\section{CONCLUSION}

The overall goal of this project was to design a modular rammed earth housing kit that could be shipped to locations that have limited resources available for home construction. This was achieved by ensuring that all of the design requirements were met and exceeded wherever possible. The final kit design offers an option that is competitive in price, weight, time of construction, and functionality when compared to options currently available on the market. The total cost of the kit is $\$ 16,720$. Each kit contains enough materials to construct ten houses, resulting in an average cost of $\$ 1,672$ per house. As an added advantage the kits offer customization in wall size, window and door size, and window and door location. The builders of the houses can decide on housing style that best meets their needs. Once on site the modules contained in the shipment package can be separated for easy transportation around the construction site. It is expected that once sufficient funding has been acquired the prototyping and implementation phases will be completed after which, commercial production will begin.

\section{ACKNOWLEDGEMENTS}

This project could not have been completed without the help of the senior design team student members Jake Frew, Josh Jones, Marshall McGinnis and Matt Pedersen and the resources of the department of Mechanical and Aerospace Engineering at the University of Colorado at Colorado Springs.

\section{REFERENCES}

${ }^{1}$ Bui Q.B., Morel J.C., Venkatarama Reddy B.V., Ghayad W. Durability of rammed earth walls exposed for 20 years to natural weathering. Building and Environment 44(2009): 912919

2 Maniatidis V., Walker P. A Review of Rammed Earth Construction. DTi Partners in Innovation Project 'Developing Rammed Earth for UK Housing' (2003)

${ }^{3}$ Bui, Q.B., Morel J.C. Accessing the anisotropy of rammed earth. Construction and Building Materials 23(2009): 3005-3011

4 Sadiqi "Wardak", Zabihullah, Coffey, Vaughan, \& Trigunarsyah, Bambang (2012) Rebuilding housing after a disaster : factors for failure. In Yamada, Fumihiko \& Kakimoto, Ryuji (Eds.) Proceedings of 8th Annual International Conference of the International Institute 
for Infrastructure, Renewal and Reconstruction (IIIRR), Kumamoto University, Kumamoto, Japan, pp. 292- 300

${ }^{5}$ Maniatidis, Vasilios, and Peter Walker. "Review of Rammed Earth." Department of Architecture and Civil Engineering. University of Bath, May 2003. Web. 22 Apr 2012.

${ }^{6}$ McHenry, Paul G. Adobe and Rammed Earth Buildings: Design and Construction. New York: John Wiley and Sons, 1989. Print.

${ }^{7}$ Okunade, E.A. "Engineering Properties of Lateritic Adobe Bricks for Local Building Construction and Recommendations for Practice." Journal of Engineering and Applied Sciences. 2. (2007): 1455-59. Web. 19 Apr. 2012.

8 "About Habitat for Humanity." Habitat for Humanity International. Habitat for Humanity, 2010. Web. 19 Apr 2012

9 "Hydraform - Sustainable Building Solutions." Hydraform. Hydraform, n.d. Web. 19 Apr 2012.

10 "Steel-Ply Forming System." Symons. Dayton Superior, Jan 2012. Web Brochure. 19 Apr 2012

${ }^{11}$ Hibbeler, R.C. Mechanics Of Materials. 8th. New Jersey: Prentice Hall, 2011. Print

12 "Design Values for Structural Glued Laminated Timber in Existing Structures." AITC Glulam. American Institute of Timber Construction, Dec 2007. W

13 "Large Glued-Laminated Timber Beams With Two Grades Of Tension Laminations U.S.D.A. Forest Service Research Paper” Fpl 113 September 1969 